\title{
Systems integration to promote the mental health of Aboriginal and Torres Strait Islander children: protocol for a community-driven continuous quality improvement approach
}

Janya McCalman ${ }^{1,2^{*}}$ (D), Roxanne Bainbridge ${ }^{2}$, Yvonne Cadet James $^{3}$, Ross Bailie ${ }^{4}$, Komla Tsey $^{5}$, Veronica Matthews ${ }^{4}$, Michael Ungar ${ }^{6}$, Deborah Askew ${ }^{7,8}$, Ruth Fagan ${ }^{9}$, Hannah Visser ${ }^{10}$, Geoffrey Spurling ${ }^{7,8}$, Nikki Percival ${ }^{11}$, Ilse Blignault ${ }^{12}$ and Chris Doran ${ }^{1,2}$

\begin{abstract}
Background: Systems integration to promote the mental health of Aboriginal and Torres Strait Islander children works towards developing a spectrum of effective, community-based services and supports. These services and supports are organised into a coordinated network, build meaningful partnerships with families and address their cultural and linguistic needs, to help children to function better at home, in school, in the community, and throughout life. This study is conducted in partnership with primary healthcare (PHC) and other services in three diverse Indigenous Australian communities. It entails conceptualising, co-designing, implementing, and evaluating the effectiveness of systems integration to promote the mental health and wellbeing of Indigenous school-aged children (4-17 years). This paper outlines a protocol for implementing such complex community-driven research.

Methods/design: Using continuous quality improvement processes, community co-designed strategies for improved systems integration will be informed by narratives from yarning circles with Indigenous children and service providers, and quantitative data from surveys of service providers and audits of PHC client records and intersectoral systems. Agreed strategies to improve the integration of community-based services and supports will be modelled using microsimulation software, with a preferred model implemented in each community. The evaluation will investigate changes in the: 1) availability of services that are community-driven, youth-informed and culturally competent; 2) extent of collaborative service networks; 3) identification by PHC services of children's social and emotional wellbeing concerns; and 4) ratio of children receiving services to identified need. Costs and benefits of improvements to systems integration will also be calculated.
\end{abstract}

(Continued on next page)

\footnotetext{
* Correspondence: j.mccalman@cqu.edu.au

'Centre for Indigenous Health Equity Research, Central Queensland University, cnr Abbott and Shield St, Cairns, QLD 4870, Australia

${ }^{2} \mathrm{~S} c h o o l$ of Health, Medical and Applied Sciences, Central Queensland

University, cnr Abbott and Shield St, Cairns, QLD 4870, Australia

Full list of author information is available at the end of the article
}

(c) The Author(s). 2020 Open Access This article is licensed under a Creative Commons Attribution 4.0 International License, which permits use, sharing, adaptation, distribution and reproduction in any medium or format, as long as you give appropriate credit to the original author(s) and the source, provide a link to the Creative Commons licence, and indicate if changes were made. The images or other third party material in this article are included in the article's Creative Commons. licence, unless indicated otherwise in a credit line to the material. If material is not included in the article's Creative Commons licence and your intended use is not permitted by statutory regulation or exceeds the permitted use, you will need to obtain permission directly from the copyright holder. To view a copy of this licence, visit http://creativecommons.org/licenses/by/4.0/. The Creative Commons Public Domain Dedication waiver (http://creativecommons.org/publicdomain/zero/1.0/) applies to the data made available in this article, unless otherwise stated in a credit line to the data. 
(Continued from previous page)

Discussion: The study will provide evidence-informed, community-driven, and tested models that can be used for implementing systems integration to promote the mental health and wellbeing of Indigenous children. It will identify the situational enablers and barriers that impact systems integration and determine the extent to which systems integration improves service availability, systems and child outcomes. Evidence for the cost effectiveness of systems-level integration will contribute to national mental health policy reform.

Keywords: Integrated care, Mental health, children's health, Indigenous health

\section{Background \\ Introduction}

The school years of childhood (aged 4-17 years) are a particularly important time for early intervention in mental health since half of all global mental health conditions start by age 14 years and three quarters by age 24 $[1,2]$. Services and supports for early intervention are variously offered by primary healthcare (PHC) services, schools, youth services, mental health services, child protection and juvenile justice services. But, as described in 14 Australian government mental health, social and emotional wellbeing (SEWB), and suicide prevention policy documents released from 2013 to 2018, the service system is complex, inefficient and fragmented [3-5]. Navigating the system is therefore a formidable challenge for service users $[5,6]$.

Efforts to improve the integration of mental healthcare services have cited a need for reprioritisation and reinvestment from crisis focussed to preventive services and from visiting services towards greater emphasis on community-based and community-controlled services [7-10]. The recent Queensland Mental Health Commission strategic plan, for example, stated that "a more balanced approach requires a shift towards the community as the key place where mental health ...services and support are provided..." ([9] , p. 31). Important in such community-driven approaches is the integration of mental health promotion and early intervention services for children across the primary and mental healthcare, education and social services sectors [11].

Aboriginal and Torres Strait Islander Australian (hereafter respectfully termed Indigenous while acknowledging cultural and historical diversity) communities share the broad goal of providing access to effective mental health promotion and care for their children and families [12, 13]. Experiences of systemic racism, low socio-economic environments, and the historic and ongoing marginalisation of Indigenous cultures place Indigenous children at elevated risk of poor mental health [10, 14-17]. However, efforts by Indigenous community leaders to identify priorities for improvement and implement decisions to improve the effectiveness of mental healthcare services and systems have met with limited government support and resourcing for local leadership e.g. $[10,17,18]$. In one discrete Indigenous community, for example, evaluators found a complex and disjointed network of 39 distinct programs delivered by 21 providers to the community's 330 children $[18,19]$. There was little evidence of service delivery coordination or case management with federal and state government competitive and short-term funding environments compelling service providers to 'stick to their own turf. The overall effects of children's programs (positive or negative) could not be determined [19]. As cited by Maddison [20] "Indigenous Affairs policy is made in a context of enormous structural inequality where [state and federal] governments hold almost all the cards".

Based on evidence that regardless of the number of risk factors, the presence and strength of protective factors are able to reduce risk [21], Indigenous Australians have developed the strengths-based concept of SEWB to capture "understandings of themselves and their experiences as they relate to mental health" [22]. SEWB manifests in how Indigenous peoples view the world, are affected by networks of relationships and power, their histories and connections to land or 'country', culture, spirituality, ancestry, family and community [23-25]. However, there is currently limited evidence for how Indigenous community-driven SEWB interventions or systems-level improvements are defined or implemented [25, 26].

Recognising the need for a more systematic and community-driven approach, Indigenous PHC and other services in three diverse communities embraced an opportunity to conceptualise, co-design, implement and evaluate integrated systems to promote the mental health of Indigenous school-aged children in their communities. Indigenous guided systems integration is defined as the development of a spectrum of effective, community-based services and supports for children's SEWB that reflect Indigenous worldviews and culture, are organised into a coordinated network, and build meaningful partnerships with families to help them to function better at home, in school, in the community, and throughout life [27]. This paper provides the protocol used to implement such complex community-driven research. Guiding this program of research, our questions are:

1 Is it feasible to conceptualise, co-design and implement systems integration that meets the 
desired goals of Indigenous communities and promotes the mental health and wellbeing of Indigenous children?

2 What systems improvements are identified to achieve Indigenous communities' goals and promote children's mental health and wellbeing?

3 Does improved community-driven integrated mental health promotion enhance the: a) availability of services that are community-driven, youth-informed and culturally competent; b) collaborative service networks to integrate systems; c) PHC-identified children's SEWB concerns; and d) ratio of children receiving services to identified need?

\section{Service fragmentation}

Indigenous-specific community controlled or government PHC services are responsible for providing a first contact point with the health system, including mental healthcare. The need for PHC to support children's mental health is evidenced by National Aboriginal and Torres Strait Islander Social Survey (NATSISS) (201415 ) results that $32 \%$ of adolescents (15-19 years) reported high levels of psychological distress [15] and Western Australian surveys that showed 26\% of children 4-11 years and $20.5 \%$ children $12-17$ years old were at high risk of clinically significant emotional or behavioural difficulties [14]. Yet evidence from 114 PHC services suggests that only $17.4 \%$ of attending Indigenous adolescent (15-19 years) clients were screened for SEWB concerns or mental health risks [28]. NATSISS also found that more than three quarters (77\%) of Indigenous adolescents with high psychological distress reported not having seen a PHC professional in the previous 12 months [15]. Furthermore, there is little evidence of the trajectories of Indigenous young people through the mental healthcare system or mental health treatment pathways developed or modified to specifically meet the needs of Indigenous adolescents [26]. Whilst PHC services are able to refer young people to youth mental health services in many urban areas, there is also evidence that Indigenous young people do not access these services commensurate with their needs [29]. Instead, the system failure to intervene early leads to a continued heavy reliance on crisis and acute services, including hospitalisation $[9,16]$. Hospitalisation costs $\$ 16,676$ per admitted patient [30] and serious mental illness is associated with lifetime adverse outcomes.

In schools, staff (including guidance counsellors and psychologists) provide counselling, case management and referral for social, emotional, and behavioural difficulties including mental illnesses, but little is known about Indigenous students' use of mental health services through schools [31]. Research from the United States suggests that schools may function as a de facto mental health service; a North Carolina study found that 70$80 \%$ of children who received services for a mental health problem were seen by education sector providers, and for most children receiving mental healthcare, this was the sole source of care [32]. Australian state and territory education departments recognise the role of health in students' engagement in learning [33], and have outlined school responsibilities for both teaching about health and managing the health and wellbeing of students while they are at school. Studies have suggested that schools could play a greater role in Indigenous students' mental (and physical) healthcare [34]. Youth services also provide a range of programs, services and facilities that promote the mental health of children, including day sports, recreation and other programs, as well as case management, therapeutic counselling, and outreach.

Despite recognition that Indigenous children are better served by investing in family support programs delivered through Indigenous organisations rather than removal and intervention, the child protection and juvenile justice sectors provide services to a vastly overrepresented Indigenous cohort (10 times and 24 times the rate for nonIndigenous children, respectively) [35, 36]. A retrospective analysis of linked data found that children reported to New South Wales protective services during early childhood were three times more likely to be diagnosed with a mental disorder during middle childhood than children without reports. Children placed in out-of-home care were five times more likely to receive such a diagnosis [37]. There is currently limited evidence about what improvements work for these children with complex needs. However, reviews suggest the need for preventive and early intervention approaches, comprehensive assessments, joined-up or wrap-around services, attachment-based interventions, placement stability and appropriately supported carers, and integrated and appropriate aftercare [38].

There is also limited evidence for interventions to integrate such fragmented intersectoral services for Indigenous children's mental healthcare. Our scoping review of systems integration across at least two sectors to improve the mental health of Indigenous children (4-17 years) [39] found only five Australian studies [40-44]. These evaluated and/or described diverse inquiries: two explored Indigenous community and service provider perspectives of access to mental healthcare with the aim of driving service improvement $[40,43]$, one described a model for consultation with Indigenous stakeholders to develop a training course [44], and two described and evaluated the process and impacts of empowerment programs for Indigenous adolescents [41, 42]. Documented enablers of implementation were the involvement of community, access and cost, collaborative multidisciplinary health services, strong 
relationships, cultural sensitivity, and organisational and staff capacity. Outcomes across the studies included health and human services linkages and collaboration; psychosocial functioning and stress management of children; development and promotion of appropriate health policy and protocols; and family, community and organisational empowerment [39]. Although this evidence is useful, it provides limited guidance and leaves Indigenous PHC services and other service providers struggling to identify what works in planning integrated mental health service approaches [12, 25, 39].

\section{Theoretical framework}

The federally funded systems of care approach for children's mental healthcare improvement in the United States (US) since 1992 has elucidated a theoretical framework for systems integration. It comprises three key components that do not comprise a separate program or 'package of activities', but dynamic elements that interact with the extant services and communities into which a continuous quality improvement approach is introduced [45]. They are: 1) a spectrum of services and supports that interact with children and families to deliver mental health promotion and care; 2) a set of values and principles; and 3) an infrastructure, including leadership and governance, financing, health information, and workforce capacity, and networks and partnerships among agencies and with families and children [27]. These are elucidated below.

The spectrum of children's mental health services and supports available in a community encompasses wellness promotion, early identification and support, and treatment for serious mental illness [46]. US community efforts to enhance systems integration have focussed on expanding the array of services and supports to ensure that families have choice of services across this spectrum [27]. Some US communities also implemented strategies to enhance three key values and principles within extant networks of care. These were: the need for approaches to be family-driven and youth guided to ensure that the types and mix of services provided were flexible and aligned with the strengths and needs of the child and family; community based to ensure that the locus of control and management of systems rests within community structures, processes and relationships; and culturally and linguistically competent by developing and utilising protocols, screening tools and mental healthcare pathways that were appropriately adapted to respond to children's needs [27]. Examples of US community strategies included enhancing family-driven and youthguided services, using evidence-informed and promising practices, improving cultural and linguistic competence and reducing racial disparities [27].
The infrastructural changes required for systems integration included considerations of leadership and governance, financing, workforce capacity, health information, and networks and partnerships among agencies and with families and children [47]. Examples of effective US governance improvements included a community locus of management and accountability, joint strategic planning and implementation, generation of policy support, and government proposals to implement systems integration requirements. Effective financing initiatives included redeploying funds from higher to lower cost services, accessing new funding streams, and block grant funding. Capacity was enhanced by staff training, technical assistance and coaching across agencies and using evidence-informed and practice-based approaches. Health information strategies included data sharing using a single client tracking system and/or shared case records, implementing or expanding the use of technology, sharing data on outcomes and economics, and using social marketing to communicate. Partnerships were cultivated through identifying strategic leaders and champions, inter-agencies and partnerships, expanding a family-centred wraparound approach, creating care management entities, improving care coordination, and adopting quality improvement and evaluation strategies [27].

This Indigenous Australian systems Integration project draws on the US systems of care theoretical framework as a guide, but will conceptualise, co-design, implement and test strategies, values, and infrastructure with and for Indigenous Australian communities. For instance, the US identified values and principles are broadly consistent with the values and principles found to underpin Indigenous Australian SEWB programs. Although these values have not been tested in Indigenous Australian communities, they are broadly consistent with the values and principles found to underpin Indigenous Australian SEWB programs. These are a family focus; Indigenousleadership, self-determination and community governance; and a holistic approach focussed on restoration and community resilience, recovery and healing from stress and trauma, cultural responsiveness, empowerment, context specificity and interdisciplinarity and partnerships $[8,13,25]$. However, these have not been tested in systems integration initiatives within Indigenous Australian communities.

In this project, community-driven systems integration is implemented through a continuous quality improvement (CQI) process. CQI approaches have been utilised in Indigenous PHC services in Australia for more than 15 years to "involve people in planning and executing a continuous flow of improvement to provide quality health care that meets or exceeds expectations" [48-50]. Traditionally, the PHC focus has been on CQI in clinical care. CQI approaches have achieved enhanced adherence 
to best practice clinical guidelines, improved regularity of client attendance [51], produced a CQI workforce and appropriate health system supports, improved organisational efficiencies and increased engagement with other organisations and community members. Promising attempts have also been made to apply CQI beyond clinical care to Indigenous food security [52], health promotion [53] and the determinants of children's health [54]. Building from this evidence, this proposed research will be the first to extend and test the value of CQI in connecting services in collaborative, participatory research to examine the dynamic, messy and interactive conditions and strategies that are needed to advance mental health systems integration [55].

\section{Aims}

In partnership with Indigenous PHC services and linked partner services in three diverse communities, this study aims to conceptualise, co-design and evaluate communitydriven systems-level integration to promote the mental health of Indigenous children. In this study, we hypothesise that in each community: 1) community-driven mental health systems integration improvements will be feasible; 2) quality improvements will increase the identification of SEWB concerns in children screened by $10 \%$ (for early identification and intervention) and improve the ratio of children receiving services to identified need by $10 \%$; and 3) improvements will have benefits that exceed costs.

\section{Methods/design}

This research has senior Indigenous leadership and sits at the interface of Indigenous and Western knowledge systems that is respectful of different cultural worldviews, values and practices. Indigenous participation, and community-based engagement and employment is embedded in the research design.

\section{The community settings}

The study builds on and consolidates pre-existing research relationships with three Indigenous PHC services: two in Queensland (QLD) and one in New South Wales
(NSW) (Table 1). The three services represent diversity in PHC service governance (government or communitycontrolled) and location (state capital city, regional town and discrete Indigenous community). Each PHC partner offers mental health services as part of their preventative health focus and approximately $30 \%$ of the regular PHC Indigenous clients are children $(n=3251)$.

\section{Research governance}

Three overlapping levels of governance inform the project's operational research management team: community health partners, a Community Youth Advisory Group and the project investigators. Community health partners from the three participating communities include representatives from the PHC services and associated service providers. Their role is to advise research implementation and provide links with appropriate services, systems and staff in each community, to champion the development of the systems integration improvements, link with project governance groups, and oversee a part-time employed community research officer. The community research officers will assist with planning, implementing and communicating the community-based project activities. The Community Youth Advisory Group comprises youth representatives (aged 1724 years) from each participating community. It is coordinated and facilitated by an Indigenous youth empowerment organisation, Deadly Inspiring Youth Doing Good (DIYD G), in coordination with the project manager. The role of the Community Youth Advisory Group is to advise youthguided ways to improve the mental health and wellbeing services and systems for Indigenous children in their communities. This ensures the centrality of the youth voice and their interests and needs. The project investigators comprise academic and community partners. They provide or recommend expert multi-disciplinary investigator advice, ensure ethical and cultural research principles are observed and practised, advise the research methods, and contribute to research capabilities and outputs. Each level of governance reports to an Indigenous-led project management

Table 1 Settings and number of clients aged 4-17 years

\begin{tabular}{|c|c|c|c|c|}
\hline PHC Collaborator & Service Type & Area Descriptor & $\begin{array}{l}\text { Child } \\
\text { clients }\end{array}$ & $\begin{array}{l}\text { \% children with } \\
\text { depression }\end{array}$ \\
\hline Gurriny Yealamucka Aboriginal Health Service & Community Controlled PHC & $\begin{array}{l}\text { Yarrabah, northern QLD. Outer regional. } \\
\text { Discrete community }\end{array}$ & 1007 & $\begin{array}{l}18 \% \mathrm{mod} / \text { severe } \\
52 \% \mathrm{mild}+{ }^{\mathrm{b}}[56]\end{array}$ \\
\hline Bulgarr Ngaru Medical Aboriginal Corporation & Community Controlled PHC & $\begin{array}{l}\text { Casino, northern NSW. Inner regional. } \\
\text { Integrated community }\end{array}$ & 504 & Not available \\
\hline $\begin{array}{l}\text { Southern Queensland Centre of Excellence in } \\
\text { Aboriginal and Torres Strait Islander Primary } \\
\text { Health Care }\end{array}$ & Government PHC & Inala, Brisbane, QLD. Major city suburb. & 1740 & $26 \%^{\mathrm{a}}[57]$ \\
\hline
\end{tabular}

Inala $=26 \%$ of $15-24$ year olds scored more than 9 on the adapted Patient Health Questionnaire (a-PHQ9)

${ }^{\mathrm{b}}$ Gurriny $=18 \%$ of $15-24$ year olds scored a-PHQ9 $>10 ; 52 \%>5$ 
team that comprises research and community representatives who are responsible for operational decisions.

\section{Study design}

This research adopts a pragmatic, prospective step-wedge design [58], with a staggered implementation of the CQI approach and a 6-monthly crossover from community one (pragmatically selected) to communities two and three. A pragmatic step-wedge design allows consideration of community and organisational contextual differences, including readiness for implementation, with the sequential implementation of the core components carefully documented in each site. The step-wedge design also assures confidence in the research findings.

\section{Methods}

In each community, a facilitated CQI approach with PHC services and linked service providers' is structured using the feasible and flexible United Kingdom Medical Research Council framework for the development and evaluation of complex interventions [59]. Three research parts link with the three hypotheses and entail: 1) a developmental evaluation approach to inform conceptualisation and co-design of systems integration improvements; 2) an impact evaluation; and 3) an economic evaluation (Fig. 1).

\begin{tabular}{|c|c|c|c|c|c|}
\hline \multirow{2}{*}{\begin{tabular}{l}
\multicolumn{1}{c}{ Hypothesis } \\
H1: Mental \\
health \\
systems \\
integration \\
improvements \\
will be \\
feasible
\end{tabular}} & \multicolumn{4}{|c|}{$\rightarrow \quad$ Methods } & \multirow{2}{*}{ 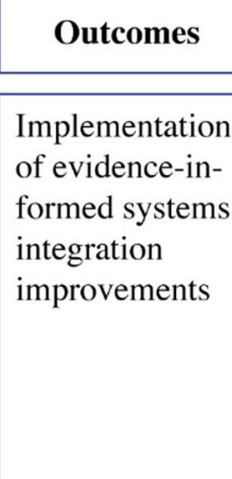 } \\
\hline & $\begin{array}{l}\text { Yarning circles } \\
\text { to produce } \\
\text { community } \\
\text { narratives of } \\
\text { children's } \\
\text { mental health } \\
\text { and service } \\
\text { availability }\end{array}$ & $\begin{array}{l}\text { Surveys of } \\
\text { service } \\
\text { availability; } \\
\text { audits of } \\
\text { systems } \\
\text { integration to } \\
\text { examine values } \\
\text { and } \\
\text { collaboration }\end{array}$ & $\begin{array}{l}\text { Audits of PHC } \\
\text { records for } \\
\text { children 5-18 } \\
\text { years in each } \\
\text { community }\end{array}$ & $\begin{array}{l}\text { Co-design of } \\
\text { proposed } \\
\text { improvements } \\
\text { in CQI work- } \\
\text { shops, with } \\
\text { simulation } \\
\text { modelling to } \\
\text { determine } \\
\text { feasibility }\end{array}$ & \\
\hline $\begin{array}{l}\text { H2: } \\
\text { improvements } \\
\text { will increase } \\
\text { identification } \\
\text { of social and } \\
\text { emotional } \\
\text { wellbeing } \\
\text { concerns in } \\
\text { children } \\
\text { screened by } \\
10 \% \text {; improve } \\
\text { ratio of } \\
\text { children } \\
\text { receiving } \\
\text { services to } \\
\text { need by } 10 \%\end{array}$ & $\begin{array}{l}\text { Further } \\
\text { facilitated } \\
\text { workshops to } \\
\text { guide the } \\
\text { implementa- } \\
\text { tion of systems } \\
\text { integration }\end{array}$ & $\begin{array}{l}\text { Repeat service } \\
\text { mapping and } \\
\text { audits } \\
12 \text {-monthly for } \\
2 \text { years; } \\
\text { staggered } \\
\text { across } \\
\text { communities }\end{array}$ & $\begin{array}{l}\text { Repeat client } \\
\text { record audits } \\
12 \text {-monthly for } \\
2 \text { years; } \\
\text { staggered } \\
\text { across } \\
\text { communities }\end{array}$ & $\begin{array}{l}\text { Assess } \\
\text { outcomes after } \\
2 \text { years within } \\
\text { and across } \\
\text { communities }\end{array}$ & $\begin{array}{l}\text { Increased } \\
\text { identification of } \\
\text { social and } \\
\text { emotional } \\
\text { wellbeing } \\
\text { concerns in } \\
\text { children } \\
\text { screened; } \\
\text { improved ratio } \\
\text { of children } \\
\text { receiving } \\
\text { services }\end{array}$ \\
\hline $\begin{array}{l}\text { H3: } \\
\text { improvements } \\
\text { will have } \\
\text { benefits that } \\
\text { exceed costs }\end{array}$ & \multicolumn{4}{|c|}{$\begin{array}{l}\text { Use Framework to Assess Impact through Translation to evaluate costs } \\
\text { and benefits within and across communities }\end{array}$} & $\begin{array}{l}\text { Identify broader } \\
\text { impacts, } \\
\text { improve value } \\
\text { for money, } \\
\text { inform PHCs } \\
\text { and policy } \\
\text { implementation }\end{array}$ \\
\hline
\end{tabular}

Fig. 1 Overview of hypotheses, research methods and outcomes 
Hypothesis 1: mental health systems integration will be feasible

CQI workshops provide a mechanism for working with PHC services and partner organisations to co-design evidence-based and locally responsive decisions to achieve systems-level integration improvements (Fig. 2). Co-design values the Indigenous worldviews and understanding of Indigenous community service providers and children/youth. It provides opportunities to build capabilities, and develops services and initiatives that are more likely to address the issues that matter to them [60].

First, yarning circles will be held in each community to provide the perspectives of adolescents aged 12-17 years, parents/carers of children aged 4-11 years, and staff members of PHC services and partner organisations. Written consent to participate will be obtained from service providers, youth aged 16 years and over, and the parent or legal guardian of children aged 4-15 years. Discussions will focus on the characteristics of a "mentally healthy" child; supports for children's mental health; the extent to which children seek mental health services from PHC, schools, and mental health, child welfare and/or juvenile justice services, and how agencies can better collaborate to support children's mental health. Surveys will also be administered to provide baseline levels of service availability and the gaps in
PHC, mental health, youth, school, juvenile justice and child protection services in each community. Audits of PHC records will be conducted to access data about the extent of SEWB concerns recorded for children (4-17 years). Audits of integration between community services and systems (leadership and governance financing, health information and workforce) will also be conducted to provide service providers' perspectives on the baseline extent of collaborative service networks.

Evidence from the theoretical framework, our systematic literature review [39] and baseline findings from community yarning circles, service surveys and audits will then be analysed to pre-determine a set of core evidence-based and "testable" improvement criteria across communities. These core criteria will be presented and negotiated at community-based CQI workshops of service partners, adolescents and families. Implementation of each core element will be tailored in each community to sustainably meet the specific needs of their local situation. The community improvements will thus become co-designed flexible multi-component approaches with standardised elements and a common core assessment framework but tailored implementation and/or activities in each setting $[13,61]$. CQI questions will be used to review the evidence and discuss community goals and priorities across each of the core components. Questions to be asked include:

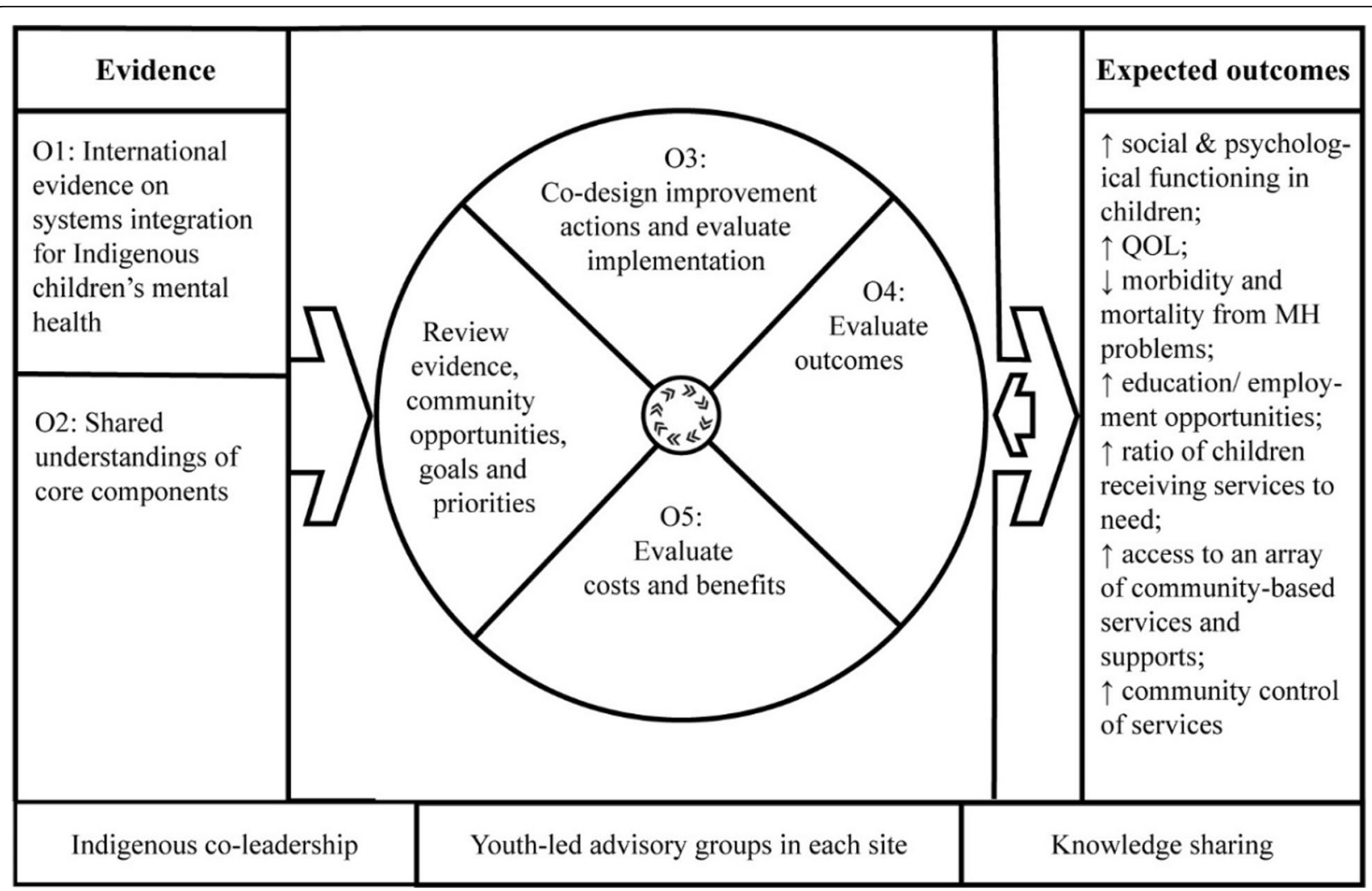

Fig. 2 the CQI cycle 
Where are we going? (Goal); What is working/not working? Who is missing out? How can we do it better? What is feasible? What improvements can we make? (Ideas); How will we know if we are making a difference? (Measurement) [62]. Grounded theory methods will be used to analyse the qualitative data from yarning circle narratives and facilitated CQI workshops [63]. A theoretical model will be developed to identify what works for whom, in what contexts, under what conditions, through which mechanisms and with what consequences.

Agreed improvement strategies will also be modelled using dynamic, discrete, event-based, microsimulation agent based modelling [64] to explore and analyse baseline systems-level integration in each community, adding the improvement decisions of each community $[45,65]$. The microsimulation modelling will determine the feasibility of decisions, for understanding and clarifying the complex effects of the intersectoral community mental health service system as a whole, and predicting likely impacts and costs of proposed improvements, without disruption in real time [66, 67]. If improvement decisions are considered not feasible, the modelling will be adjusted until a desirable outcome is achieved. Once feasible, the co-designed quality improvements to systems integration will then be implemented by PHCs in each community.

\section{Hypothesis 2: improvements will produce impact}

The outcomes of the co-designed improvements implemented in each PHC will be assessed by analysing changes over 2 years compared with the baseline level from each community (Fig. 3). Where possible, quantitative measures are derived from routinely collected data to measure systems integration improvement outcomes [13]. Measures will be refined based on the goals and priorities of each community and the findings from the yarning circles. The key indicators are: 1) Availability of a spectrum of community-based services that are values-based - a survey instrument tailored to Indigenous Australian contexts from the Service System Inventory used in Canadian Circles of Care interventions [68] will be administered by researchers to community mental health services to measure the extent to which: a) Indigenous children receive mental health-related services; and b) they are community-driven, youth-informed and culturally competent. 2) Systems integration -A modified Health Promotion Systems Assessment Tool (HPSA $\mathrm{T}$ ) will be used to audit community-level leadership and governance, financing, workforce capacity, and health information infrastructure for systems integration, and networks and partnerships among agencies and with families and children [53]. 3) Children's SEWB concerns - modified child (5-11 years) health [69] and youth (12-17 years) health clinical audit tools [70] will be used to audit the PHC records of children's attendance at the health service, reason for attendance, and discussions/ brief intervention/ advice about SEWB in the last 12 months (modified to also audit concerns identified). The youth health clinical audit tool has a specific focus on SEWB and also incorporates items for mental health-related long-term health conditions and

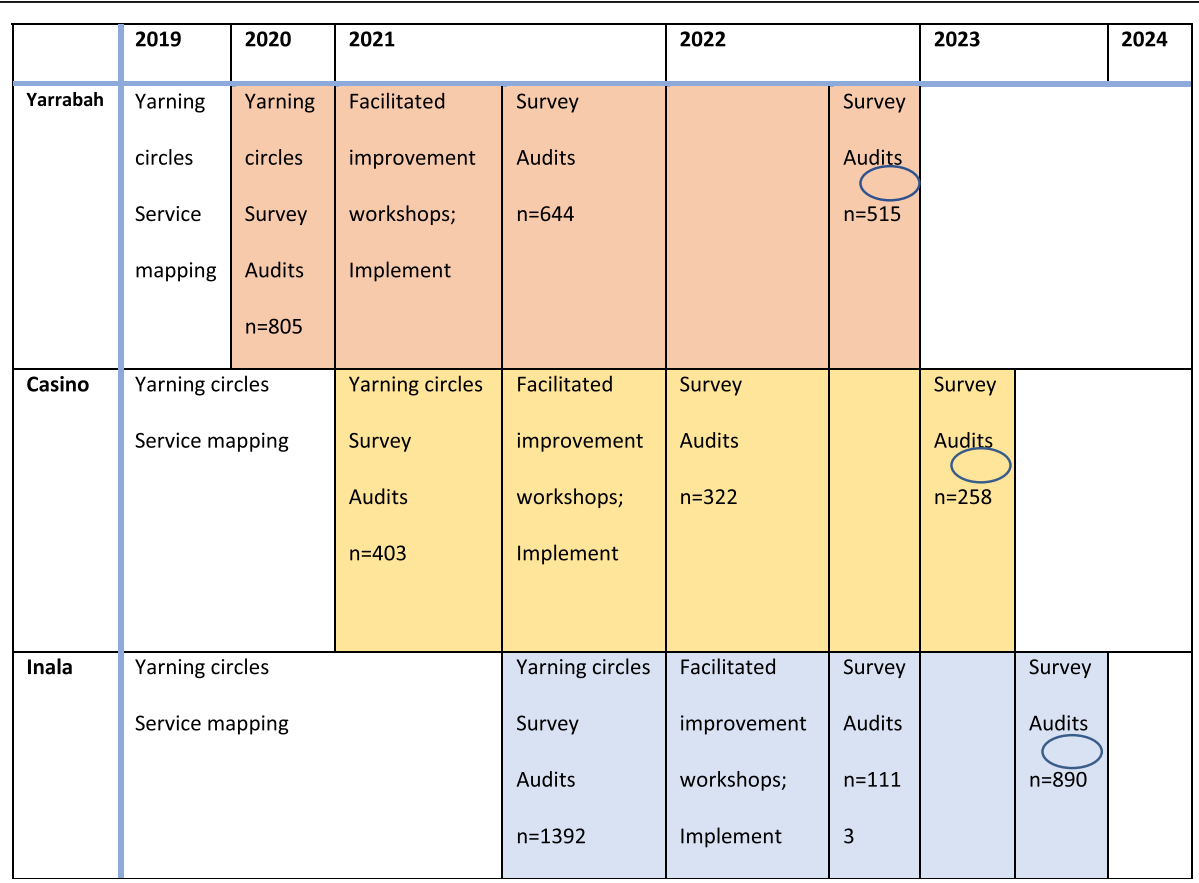

Fig. 3 Pragmatic step-wedge design, population, research activities and indicative sample sizes 
management plan, emotional wellbeing assessment, documented concerns, recorded risk status for suicide and self-harm, actions taken, actions reviewed, referral and follow up. The actual measurement tool used may differ by PHC service and age, for example Inala and Yarrabah use the Strengths and Difficulties Questionnaire for children 5-14 years and the adapted Patient Health Questionnaire for children aged 15 years+, but important here is the identification of need regardless of the measurement tool used. 4. Ratio of children receiving services to identified need - the ratio of children receiving mental health services to identified need will be determined by the number of Indigenous children receiving mental health-related services (survey results) compared to the number of children identified with SEWB concerns (PHC audits). The identification of need (through audits) is likely to vastly underestimate actual need but provides an indicator and base for improvement actions.

Survey and audit results will be analysed for demographic comparability between communities. Logistic regression will be completed to determine the effect of the improvement on audit scores from baseline to subsequent cycles and to assess the cycle trend. The association between the audit scores over time will be tested by fitting multilevel logistic regression models. Potential confounding variables will be explored to assess their impact on outcomes of interest, with missing data and drop-outs described. Probabilistic sensitivity and uncertainty interval analyses will be conducted to examine uncertainty around impact assessments. Cross-community comparisons will also be analysed.

\section{Hypothesis 3: improvements will have benefits that exceed costs}

The economic evaluation will apply the Framework to Assess Impact through Translation (FAIT) to test the benefits and costs of the systems integration improvements [71]. The FAIT employs a combination of quantified metrics (a modified form of Payback) [72], economic assessment (using a social return on investment), and narratives of the process as the research translates and generates impact. To produce high impact, policy relevant research outputs, the economic cost and benefits of all quality improvements will be tested in the study [71].

\section{Discussion}

This study contributes to the development of Indigenous children's, family and community, PHC and government agendas for quality improvements in mental health and Indigenous health. It will achieve this by improving access to, the quality and efficiency of, and outcomes and impacts from integrated mental health systems and services for Indigenous children [73]. The documented benefits of systems integration include improvements in clinical and functional outcomes, behavioural and emotional strengths, school performance and attendance, more stable living situations; and reductions in suicide attempts, contacts with law enforcement, and reliance on inpatient care [27]. For families benefits are likely to include improvements in overall family functioning and adequate resources; reductions in strain associated with caring for a child with a mental illness, and missed days of work due to the mental health needs of the child [27]. The pragmatic benefits of the project for the three participating communities are likely to include improvements in the availability and coordination of mental health services, and evidence for advocating the reinvestment of funding from crisis focussed and visiting services to community-based and upstream (preventive) community-driven and controlled services.

This innovative and important study is being conducted during major reform of both the Australian mental health and Indigenous health systems. It will generate evidence to inform national and state efforts to improve both integration of the current fragmented state of mental health care [74], and health equity [73, 74]. It will contribute prominently to the 2016 National Mental Health Commission review recommendations for investment in an integrated prevention and early intervention approach, a focus on Indigenous Australians, support for children, use of evidence-based practice, and consistent outcome measures [74]. Expected research outcomes from this project include: 1) feasible and tested Indigenous community-driven systems integration models to promote, identify concerns and provide early support for the mental health of Indigenous children; 2) new knowledge of the extent to which systems integration improves the accessibility and quality of Indigenous children's mental health services and their capacity to meet need; and 3) evidence of the economic impact of systems-level integration, informing opportunities for reducing the annual \$60 billion national cost of mental ill-health [74].

Thus, the study fills fundamental gaps in the evidence to guide pragmatic efforts by Indigenous community PHC, Primary Health Networks and other sectors to optimally integrate systems to promote the mental health of Australia's 263,000 Indigenous children. The considerable and growing population (33\% of the Indigenous population) of Indigenous school-aged children offers undeniable strengths, including their potential as healthy, productive and engaged citizens. The study contributes to supporting and enhancing children's wellbeing and potential by identifying new models for community-based and integrated mental health promotion and early intervention that are based on knowledge produced from each of the diverse communities. These improvements are underpinned by partnerships, engagement, collaboration, agreed values, participatory CQI, 
and tailored workforce training in systems integration approaches. The study also contributes to a specific policy focus on Indigenous children's wellbeing - a necessary focus if the Australian government's new Closing the Gap socio-economic targets are to be attained [75-77].

\section{Abbreviations}

aPHQ9: Adapted Patient Health Questionnaire; CQI: Continuous quality improvement; DIYDG: Deadly Inspiring Youth Doing Good; FAIT: Framework to Assess Impact through Translation; HPSAT: Health Promotion Systems Assessment Tool; NATSISS: National Aboriginal and Torres Strait Islander Social Survey; NSW: New South Wales; PHC: Primary healthcare; QLD: Queensland; SEWB: Social and emotional wellbeing; US: United States

\section{Acknowledgements}

Tina McDonald read and edited final versions of the manuscript. Alexandra van Beek, Sandra Campbell and Tina McDonald managed early research processes for the project.

\section{Authors' contributions}

$\mathrm{JM}$ and RB1 conceptualised the study and JM drafted the manuscript. RB2, VM and KT contributed to the CQI design; YCJ, RB, KT, VM, DA, RF, HV and GS contributed to the community-designed approach, MU contributed to the study's resilience focus, KT, NP and IB contributed to the health promotion systems approach and measurement tools, CD designed the economic analysis. All authors read and approved the final manuscript.

\section{Authors' information}

RB1, YCJ, VM and RF are Indigenous Australians; JM, RB2, KT, DA, NP, IB, HV, GS, TM and CD are non-Indigenous Australians. MU is a non-Indigenous Canadian. DA, RF, HV and GS represent the partner PHC services.

\section{Funding}

The five-year study was funded by the National Health and Medical Research Council (GNT1164251). The funding body played no role in the design of the study or in writing the manuscript.

\section{Availability of data and materials}

\section{Not applicable.}

\section{Ethics approval and consent to participate}

The design of the research governance model for the project will ensure that Indigenous research principles are embedded throughout the life of the project. The National Health and Medical Research Council guidelines for the ethical conduct of Indigenous research will guide all aspects of the research by enacting principles of spirit and integrity, cultural continuity, equity, respect, reciprocity, and responsibility [78]. Phase one of the study has received ethics approvals from Metro South Health Research Ethics Committee (HREC/2020/QMS/57760), NSW Aboriginal Health and Medical Research Council (1501/19), Central Queensland University (0000021644), NSW Department of Education (SERAP 2020164) and Queensland Department of Education (550/27/2319). Written consent to participate will be obtained from service providers, youth aged 16 years and over, and the parent or legal guardian of children aged 4-15 years. Details of managing specific ethical concerns will be developed in collaboration with PHC staff and investigators under the guidance of the Indigenous co-led project management group. Of utmost consideration is the safety of the children, and other collaborators.

\section{Consent for publication}

Not applicable.

\section{Competing interests}

The authors declare that they have no competing interests.

\section{Author details}

${ }^{1}$ Centre for Indigenous Health Equity Research, Central Queensland University, cnr Abbott and Shield St, Cairns, QLD 4870, Australia. ${ }^{2}$ School of Health, Medical and Applied Sciences, Central Queensland University, cnr Abbott and Shield St, Cairns, QLD 4870, Australia. ${ }^{3}$ Apunipima Cape York
Health Council, 186 McCoombe St, Cairns, QLD 4870, Australia. ${ }^{4}$ University Centre for Rural Health, The University of Sydney, 61 Uralba St, Lismore, NSW 2480, Australia. ${ }^{5}$ The Cairns Institute, James Cook University, McGregor Rd, Cairns, QLD 4878, Australia. ${ }^{6}$ Resilience Research Centre, Dalhousie University, 6420 Coburg Rd, Halifax, NS B3H 4R2, Canada. ${ }^{7}$ Primary Care Clinical Unit, The University of Queensland, Brisbane, Qld 4072, Australia. ${ }^{8}$ Southern Queensland Health Centre of Excellence in Aboriginal and Torres Strait Islander Primary Healthcare, Building 2/37 Wirraway Parade, Inala, QLD 4077, Australia. ${ }^{9}$ Gurriny Yealamucka Health Service, Bukki Rd, Yarrabah, QLD 4871, Australia. ${ }^{10}$ Bulgarr Ngaru Medical Aboriginal Corporation, 153 Canterbury St, Casino, NSW 2470, Australia. ${ }^{11}$ Australian Centre for Public and Population Health Research, Faculty of Health, University of Technology Sydney, 235 Jones St, Ultimo, NSW 2007, Australia. ${ }^{12}$ Translational Health Research Institute, University of Western Sydney, School of Medicine, Campbelltown Campus, NSW 2560, Australia.

Received: 29 September 2020 Accepted: 12 November 2020

Published online: 27 November 2020

\section{References}

1. Kieling C, Baker-Henningham H, Belfer M, Conti G, Ertem I, Omigbodun O, et al. Child and adolescent mental health worldwide: evidence for action. Lancet. 2011;378(9801):1515-25..

2. World Health Organization. Child and adolescent mental health. Geneva: WHO; 2020.

3. The Lowitja Institute. Journeys to Healing and Strong Wellbeing Final Report. Melbourne: The Lowitja Institute; 2018.

4. National Mental Health Commission. Report of the review of mental health Programmes and services. Sydney: NMHC; 2014.

5. Ellis LA, Churruca K, Braithwaite J. Mental health services conceptualised as complex adaptive systems: what can be learned? Int J Ment Heal Syst. 2017; 11(1):43..

6. Ungar M. Resilience, trauma, context, and culture. Trauma Violence Abuse. 2013;14(3):255-66..

7. Haswell-Elkins M, Reilly L, Fagan R, Ypinazar V, Hunter E, Tsey K, et al. Listening, sharing understanding and facilitating consumer, family and community empowerment through a priority driven partnership in far North Queensland. Australasian Psychiatry. 2009;17:S54-S8.

8. Queensland Health. Queensland Health Aboriginal and Torres Strait Islander Mental Health Strategy 2016-2021. In: Aboriginal and Torres Strait islander health branch DoH. Brisbane: Queensland Health; $2016 .$.

9. Queensland Mental Health Commission. Shifting minds Queensland Mental Health, Alcohol and Other Drugs Strategic Plan2018-2023. Brisbane: QMHC; 2018.

10. Young C, Craig JC, Clapham K, Williams S, Williamson A. Stressful life events and resilience among carers of aboriginal children in urban New South Wales: cross-sectional findings from the study of environment on aboriginal resilience and child health (SEARCH). BMJ Open. 2018;8(6):e021687.

11. Rosenberg S. Shangri-La and the integration of mental health care in Australia. Public Health Res Pract. 2017; 27(3):e273723.

12. Dudgeon P, Walker R, Scrine C, Shepherd C, Calma T, Ring I. Effective strategies to strengthen the mental health and wellbeing of aboriginal and Torres Strait islander people: Closing the Gap Clearinghouse; 2014.Canberra, Australia.

13. Friedman RM, Israel N. Research and evaluation implications: Using research and evaluation to strengthen systems of care. In: BSG B, editor. The system of care handbook: Transforming mental health services for children, youth and families. Baltimore: Paul H. Brookes Publishing Co; 2008. p. 689.

14. Zubrick S, Lawrence D, Silburn S, Blair E, Milroy H, Wilkes T, et al. The Western Australian aboriginal child health survey: the health of aboriginal children and young people. Perth: Telethon Institute for Child Health Research; 2004.

15. Australian Institute of Health and Wellbeing. Aboriginal and Torres Strait Islander adolescent and youth health and wellbeing 2018: in brief. In: AlHW, editor. Canberra: Australian Government; 2018. p. 1-33.

16. Mission Australia, Black Dog Institute. Youth mental health report. Sydney: Youth Survey 2012-16; 2017

17. Blair E, Zubrick S, Cox A. On behalf of the WAACHS steering committee. The Western Australian aboriginal child health survey: findings to date on adolescents. Med J Aust. 2005;183(8):433-5. 
18. Bainbridge R, Tsey K, Andrews R, McCalman J, Brown C. Managing topdown change with bottom-up leadership: developing a community social and emotional wellbeing action framework in Aboriginal Australia. J Aust Indigenous Issues. 2013;16(2):2-20.

19. Staines Z, Moran M. Complexity and hybrid effects in the delivery and evaluation of youth programmes in a remote indigenous community. Aust J Public Adm. 2020;79(1):3-25.

20. Maddison S. Black politics. Inside the complexity of aboriginal political culture. Sydney: Allen and Unwin; 2009. p. 294.

21. Resnick MD, Bearman PS, Blum RW, Bauman KE, Harris KM, Jones J, et al. Protecting adolescents from harm: findings from the National Longitudinal Study on adolescent health. JAMA. 1997;278(10):823-32.

22. Garvey D. A review of the social and emotional wellbeing of indigenous Australian peoples - considerations, challenges and opportunities Perth: Australian indigenous health InfoNet; 2008.

23. Gee G, Dudgeon P, Schultz C, Hart A, Kelly K. Aboriginal and Torres Strait islander social and emotional wellbeing. In: HMRW PD, editor. Working together: aboriginal and Torres Strait islander mental health and wellbeing principles and practice. Canberra: Commonwealth of Australia; 2014. p. 55-68.

24. Commonwealth of Australia. National Strategic Framework for Aboriginal and Torres Strait Islander Peoples' Mental Health and Social and Emotional Wellbeing 2017-2023. Canberra: Cabinet DotPMa; 2017.

25. Bainbridge R, McCalman J, Jongen C, Kinchin I, Langham E, Campbell S, et al. Evidence check: improving social and emotional wellbeing for aboriginal and Torres Strait islander people. Sydney: Sax Institute and Beyond Blue; 2018.

26. Kilian A, Williamson A. What is known about pathways to mental health care for Australian aboriginal young people? Int J Equity Health. 2018; 17(1):12.

27. Stroul BA, Friedman R. Issue brief: strategies for expanding the system of care approach. Washington, DC: Technical Assistance Partnership for Child and Family Mental Health; 2011.

28. Langham E, McCalman J, Matthews V, Bainbridge RG, Nattabi B, Kinchin I, et al. Social and Emotional Wellbeing Screening for Aboriginal and Torres Strait Islanders within Primary Health Care: A Series of Missed Opportunities? Front Public Health. 2017;5(159):1-9.

29. headspace. headspace innovative support for Aboriginal and Torres Strait Islander youth mental health 2018.

30. Independent Hospital Pricing Authority. National Hospital Cost Data Collection; 2020. p. 21.

31. McCalman J, Langham E, Benveniste T, Wenitong M, Rutherford K, Britton A et al. Integrating healthcare services for indigenous Australian students at boarding schools: a mixed-methods sequential explanatory study. Int J Integr Care. 2020;20(8):1-16.

32. Burns BJ, Costello EJ, Angold A, Tweed D, Stangl D, Farmer EMZ, et al. Children's Mental Health Service Use Across Service Sectors Health Affairs 1995;14(3):147-159.

33. Albright A, Bundy DAP. The global Partnership for Education: forging a stronger partnership between health and education sectors to achieve the sustainable development goals. Lancet Child Adolesc Health. 2018;2(7):473474.

34. McCalman J, Benveniste T, Wenitong M, Saunders V, Hunter E. "It's all about relationships": the place of boarding schools in promoting and managing health and wellbeing of aboriginal and Torres Strait islander secondary school students. Child Youth Serv Rev. 2020;113:104954.

35. Australian Institute of Health and Welfare. Child protection Australia 201819: AlHW, Canberra; 2020.

36. Productivity Commission. Child protection services. In: Commission P, editor. Report on government services 2018. Canberra: Australian Government; 2018.

37. Green MJ, Hindmarsh G, Kariuki M, Laurens KR, Neil AL, Katz I, et al. Mental disorders in children known to child protection services during early childhood. Med J Aust. 2020;212(1):22-8.

38. Centre OTE. Evidence brief: complex needs. Wellington, New Zealand: Oranga Tamariki-ministry for Children; 2018.

39. Lopez-Carmen V, McCalman J, Benveniste T, Askew D, Spurling G, Langham $E$, et al. Working together to improve the mental health of indigenous children: a systematic review. Child Youth Serv Rev. 2019;104:104408.
40. Hinton R, Kavanagh D, Barclay L, Chenhall R, Nagel T. Developing a best practice pathway to support improvements in indigenous Australians' mental health and well-being: a qualitative study. BMJ Open. 2015;5:1-9.

41. Kowanko I, Stewart T, Power C, Fraser R, Love I, Bromley T. An Aboriginal family and community healing program in metropolitan Adelaide: description and evaluation. Aust Indigenous Health Bull. 2009;9(4):14 http:// healthbulletin.org.au/articles/an-aboriginal-family-and-community-healingprogram-in-metropolitan-adelaide-description-and-evaluation/. Accessed 10/ 11/2020.

42. McCalman J, Tsey K, Baird B, Connolly B, Baird L, Jackson R. Bringing back respect: the role of participatory action research in transferring knowledge from an aboriginal men's group to youth programs. Australasian Psychiatry. 2009:17:S59-63.

43. Liu D, de Crespigny C, Procter N, Kelly J, Francis H, Posselt M, et al. Comorbidity action in the north: a study of services for people with comorbid mental health and drug and alcohol disorders in the northern suburbs of Adelaide. Australasian Psychiatry. 2016;24(6):592-7.

44. Hillin A, McAlpine R, Bennett B, Brideson T, Worral V, Montague R. A model for consultation with aboriginal stakeholders about young people's mental health and wellbeing: the NSW school-link training program. Australasian Psychiatry. 2008;16(5):326-32.

45. Petticrew M, Knai C, Thomas J, Rehfuess EA, Noyes J, Gerhardus A, et al. Implications of a complexity perspective for systematic reviews and guideline development in health decision making. BMJ Glob Health. 2019;4:e000899.

46. Keyes CLM. The mental health continuum: from languishing to flourishing in life. J Health Soc Behav. 2002;43(2):207-22.

47. Waldrop MM. Complexity: the emerging science at the edge of order and Chaos. New York: Simon \& Schuster; 1992.

48. Sollecito W, Johnson J. McLaughlin and Kaluzny's continuous quality improvement in health care. Burlington, MA: Jones \& Bartlett Learning; 2013. p. 597.

49. Bailie R, Sibthorpe B, Gardner K, Si D. Quality improvement in indigenous primary health care: history, current initiatives and future directions. Aust J Prim Health. 2008;14(2):53-7.

50. McCalman J, Bailie R, Bainbridge R, McPhail-Bell K, Percival N, Askew D, et al. Continuous quality improvement and comprehensive primary healthcare: a systems framework to improve service quality and health outcomes. Front Public Health. 2018;6(76):1-6.

51. Matthews V, Schierhout G, McBroom J, Connors C, Kennedy C, Kwedza R, et al. Duration of participation in continuous quality improvement: a key factor explaining improved delivery of type 2 diabetes services. BMC Health Serv Res. 2014;14(1):578

52. Brimblecombe J, van den Boogaard C, Wood B, Liberato S, Brown J, Barnes A, et al. Development of the good food planning tool: a food system approach to food security in indigenous Australian remote communities. Health Place. 2015;34:54-62.

53. Percival N, O'Donoghue L, Lin V, Tsey K, Bailie R. Improving health promotion using quality improvement techniques in Australian Indigenous primary health care. Front Public Health. 2016;4(53):1-9.

54. McDonald E, Bailie R, Morris P. Participatory systems approach to health improvement in Australian aboriginal children. Health Promot Int. 2014; 32(1):62-72.

55. Patton $M Q$, Wesley F, Zimmerman B. Getting to maybe: complexity science in Service of Social Innovation. Toronto: Random House Canada; 2006.

56. Gurriny Yealamucka Health Service. Centre for Chronic Disease Prevention Yarrabah young person's health check draft report. Cairns: James Cook University; 2016

57. Spurling G. In: McCalman J, editor. Number and proportion of clients reporting social determinants, psychological distress, and psychosocial stressors (negative life events scale) by age group who had their health assessment at the Inala indigenous health service in 2017 ( $N=1123)$. Inala: Inala Indigenous health Service; 2017.

58. Copas A, Lewis, J Thompson J, Davey C, Baio, G. et al. Designing a stepped wedge trial: three main designs, carry-over effects and randomisation approaches. Trials. 2015;16(352):1-12.

59. Craig P, Dieppe P, Naclntyre S, Mitchie S, Nazareth I, Pettigrew M. Developing and evaluating complex interventions: the new Medical Research Council guidance. Br Med J. 2008;337:979-83. 
60. Lifehack. Lifehack: Enhancing the conditions for young people to flourish in Aotearoa. New Zealand Prime Minister's Youth Mental Health Project Initiative, New Zealand Government; 2017 November 2017.

61. Semczuk M, Shakeshaft A, Knight A, Maple M, McKay K, Shakeshaft B. An analysis of the relationship between a community-based prevention program for young people with multiple and complex needs and the prevalence of crime. Sydney: NDARC, UNSW; 2012.

62. Bainbridge R, McCalman J, Tsey K. Aboriginal Australian wellbeing: Evidence from a decade of community-based participatory research. Int J Health Wellness Soc. 2012;1 (2):13-28.

63. Bainbridge R, McCalman J, Whiteside M. Being, knowing and doing: a phronetic approach to constructing grounded theory with indigenous partners. Qual Health Res. 2013;23(2):275-88.

64. Sharif $B$, Kopec J, Wong $H$, Wong $H$, Finès $P$, Sayre $E$, et al. Uncertainty analysis in population-based disease microsimulation models. Epidemiol Res Int. 2012;610:1-14.

65. Rickles D, Hawe P, Shiell A. A simple guide to chaos and complexity. J Epidemiol Community Health. 2007;61:933-7.

66. Bainbridge R, McCalman J, Redman-MacLaren M, Whiteside M. Grounded theory as systems science: working with indigenous nations for social justice. In: Bryant ACK, editor. Sage handbook of grounded theory. Thousand Oaks: Sage; in press.

67. Arnold RD, Wade JP. A definition of systems thinking: a systems approach. Procedia Comput Sci. 2015;44:669-78.

68. Novins D. Service system inventory. Describing the existing service system; 2012.

69. Strobel N, Moylan C, Durey A, Edmond K, McAuley K, McAullay D. Understanding an aboriginal and Torres Strait islander child's journey through paediatric care in Western Australia. Aust N Z J Public Health. 2020; 44(2):95-101.

70. Puszka S, Nagel T, Matthews V, Mosca D, Piovesan R, Nori A, et al. Monitoring and assessing the quality of care for youth: Developing an audit tool using an expert consensus approach. Int J Ment Heal Syst. 2015;9(1):112.

71. Searles A, Doran C, Attia J, Knight D, Wiggers J, Deeming S, et al. An approach to measuring and encouraging research translation and research impact. Health Res Policy Syst. 2016;14(1):60.

72. Buxton M, Hanney S. How can payback from health services research be assessed? J Health Serv Res Policy. 1996;1 (1):35-43.

73. Department of the Prime Minister and Cabinet. In: Do PMC, editor. National Strategic Framework for Aboriginal and Torres Strait Islander Peoples' Mental Health and Social and Emotional Wellbeing 2017-2023. Canberra; 2017.

74. National Mental Health Commission. The 2016 report on mental health and suicide prevention. Sydney: NMHC; 2017.

75. Azzopardi P, Blow N, Purcell T, Brown N, Ritchie T, Brown A. Investing in the health of aboriginal and Torres Strait islander adolescents: a foundation for achieving health equity. Med J Aust. 2020;212:202-4.

76. Azzopardi PS, Sawyer SM, Carlin JB, Degenhardt L, Brown N, Brown AD, et al. Health and wellbeing of indigenous adolescents in Australia: a systematic synthesis of population data. Lancet. 2018;391:766-82.

77. Sharma R, Henneman L, Qadri A, Sharma R, Vignoles L. In: McCormick K, editor. 2017 global youth wellbeing index. Baltimore: International Youth Foundation; 2017.

78. National Health and Medical Research Council. In: NHMRC, editor. Ethical conduct in research with Aboriginal and Torres Strait Islander Peoples and communities: Guidelines for researchers and stakeholders. Canberra: Commonwealth of Australia; 2018.

\section{Publisher's Note}

Springer Nature remains neutral with regard to jurisdictional claims in published maps and institutional affiliations.

Ready to submit your research? Choose BMC and benefit from:

- fast, convenient online submission

- thorough peer review by experienced researchers in your field

- rapid publication on acceptance

- support for research data, including large and complex data types

- gold Open Access which fosters wider collaboration and increased citations

- maximum visibility for your research: over $100 \mathrm{M}$ website views per year

At BMC, research is always in progress.

Learn more biomedcentral.com/submissions 